\title{
3 Chronic release of tailless phage particles from Lactococcus lactis \#
}

4

5

6

7

8

9

2 NIZO B.V., Ede, the Netherlands

11

3 Amsterdam UMC, University of Amsterdam, Department of Rheumatology \& Clinical Immunology and Department of Experimental Immunology, Amsterdam, the Netherlands.

13

4 TI Food and Nutrition, Wageningen, the Netherlands

14

15

* Correspondence: Eddy J.Smid eddy.smid@wur.nl

\# These authors contributed equally to this work. Both authors are female, contributed equally to the research as well as writing of the manuscript. The first listed author finalized the manuscript. 


\section{Abstract}

Lactococcus lactis strains residing in the microbial community of a complex dairy starter culture named "Ur" are hosts to prophages belonging to the family Siphoviridae. L. lactis strains (TIFN1 to TIFN7) showed detectable spontaneous phage production and release $\left(10^{9}-10^{10}\right.$ phage particles $\left./ \mathrm{mL}\right)$ and up to 10 -fold increases upon prophage induction, while in both cases we observed no obvious cell lysis, typically described for the lytic life cycle of Siphoviridae phages. Intrigued by this phenomenon, we investigated the host-phage interaction using strain TIFN1 (harboring prophage proPhi1) as a representative. We confirmed that during the massive phage release, all bacterial cells remain viable. Further, by monitoring phage replication in vivo, using a green fluorescence protein reporter combined with flow cytometry, we demonstrated that the majority of the bacterial population (over $80 \%$ ) is actively producing phage particles when induced with mitomycin $C$. The released tailless phage particles were found to be engulfed in lipid membranes, as evidenced by electron microscopy and lipid staining combined with chemical lipid analysis. Based on the collective observations, we propose a model of phage-host interaction in L. lactis TIFN1, where the phage particles are engulfed in membranes upon release, thereby leaving the producing host intact. Moreover, we discuss possible mechanisms of chronic, or non-lytic release of LAB Siphoviridae phages and its impact on the bacterial host.

\section{Introduction}

Bacteriophages are highly diverse in shape, structure and composition. They can be icosahedral, spherical, pleomorphic, filamentous, droplet-, bottle- and spindle-shaped; some are with a long or short tail, some are tailless, engulfed in a lipid bilayer or containing lipids beneath the protein capsid; the genetic material can be double-stranded or single-stranded, DNA or RNA $(1,2)$. The broad accessibility of high-throughput sequencing technologies also revealed a high degree of genetic diversity in bacteriophages; mosaic genomes and numerous novel sequences of unknown function have been reported (3-6). Over $90 \%$ of reported phages are tailed double-stranded DNA phages belonging to the order Caudovirales (7). Tailed phages primarily interact with their host cell by using tail fibers and baseplate structures, and use the tail for penetrating the bacterial cell surface and viral DNA injection $(8,9)$. At the end of infection cycle, virulent tailed phage particles are released from the cells by holin-lysin induced lysis of the host. So called temperate bacteriophages undergo an alternative, lysogenic cycle in which the bacteriophage DNA integrates into the chromosome of the 
host becoming a prophage $(10,11)$. In this dormant state the prophage can replicate its genome as a part of the bacterial chromosome. Under conditions insulting its host's DNA integrity the prophage can enter the lytic cycle meaning that it excises from the bacterial chromosome, replicates its genome, assembles into mature phage particles and escapes the host following phage holin-lysin induced cell burst $(12,13)$.

About $4 \%$ of the described bacteriophages lack genes encoding tail proteins and they represent polyhedral, filamentous or pleomorphic phages. Tailless phages use other attachment devises, such as protein complexes or spikes at exposed surface sites (14-16). Some members of this group also apply alternative strategies to release their progeny from infected bacteria. Filamentous phages of the Inoviridae family are assembled at the cell surface and excreted from infected cells continuously by extrusion, a process mediated by membrane translocation and channel proteins and that leaves the host cells fully viable $(17,18)$. Another distinct mechanism of progeny release is budding, a delicate mechanism typical for animal viruses. During budding these viruses are encapsulated by the cell membrane and released, without killing the host. So far, budding has been suggested only for the family of Plasmaviridae, tailless phages infecting wall-less bacteria Acholeplasma species via membrane fusion $(19,20)$. In contrast to lytic phage release that kills the host, the non-lytic release is also referred to as chronic release (21). The group of tailless phages includes bacteriophages that have, in addition to nucleic acid and proteins, internal or external lipid constituents - a property originally associated with viruses infecting multicellular eukaryotes. Currently, the lipid-containing bacteriophages are classified into four families, Corticoviridae, Cystoviridae, Plasmaviridae and Tectiviridae (22).

Notably, all currently known phages infecting lactic acid bacteria (LAB) are members of the Caudovirales order (7), or tailed phages. Bacterium-phage interactions play a key role in the evolution of both partners in the interaction. Earlier, we described (pro)phages abundantly released and coexisting within a naturally evolved microbial community - mixed (originally und efined) complex starter culture of $L A B$ used in dairy fermentations (23). These cultures represent an interesting model ecosystem because it was established through long term propagation by back-slopping. Practicing back-slopping creates the boundaries for natural selection which drives adaptive evolution of the culture and its constituent microbial strains.

Based on analysis of the genomic content the isolated (pro)phages belong to P335 group lactococcal phages of Siphoviridae family, order Caudovirales. However, they possess some peculiar features: phage particles are abundantly released spontaneously and further stimulated by mitomycin $C$ induction (23). They appear to be tailless due to disruptions in tail-protein encoding genes (6). Moreover, the release of the (pro)phages from the host cells was not accompanied by detectable cell 
Iysis, a phenomenon which is typical for release of Siphoviridae bacteriophages (24-27). We set out to investigate this phenomenon in this study. Here we demonstrate that the tailless Siphoviridae phage particles are enclosed in lipid membrane and are released from the cells by a non-lytic mechanism, a phenomenon not described before in LAB phages.

\section{Materials and methods}

\section{Strains and media}

All Lactococcus lactis strains used in this study were statically cultivated in M17 broth (OXOID) with $0.5 \%\left(\mathrm{wt} / \mathrm{vol}\right.$ ) lactose addition (OXOID) at $30^{\circ} \mathrm{C}$, unless specified otherwise. All Escherichia coli strains harboring plasmids used in this study were cultivated at $37^{\circ} \mathrm{C}$, in $\mathrm{LB}$ broth (BD Difco) supplemented with $150 \mu \mathrm{l} / \mathrm{ml}$ erythromycin and shaken at $120 \mathrm{rpm}$.

\section{Cell growth, prophage induction, phage purification and quantification}

Overnight cultures in M17 broth supplemented with $0.5 \%$ lactose (LM17) were diluted up to $\mathrm{OD}_{600 \mathrm{~nm}}$ $=0.2$ and allowed to grow for 1 hour at $30 \circ \mathrm{C}$ before mitomycin $\mathrm{C}$ (MitC) was added (final concentrations of $1 \mu \mathrm{g} / \mathrm{ml}$ ). For control purposes, the same diluted cultures without MitC were used. Incubation proceeded for 6 or 7 hours and the turbidity at $600 \mathrm{~nm}$ was monitored at 1 hour intervals. At the end of induction the total cell number was determined by direct counting in a haemocytometer chamber and the viable count was made by a standard spread plating on M17 agar supplemented with $0.5 \%$ lactose. Released phage particles were concentrated from the culture supernatants by $\mathrm{PEG} / \mathrm{NaCl}$ precipitation as previously described (6), and the quantity was estimated based on phage DNA content in culture supernatants or in $\mathrm{PEG} / \mathrm{NaCl}$ concentrated phage suspensions using agarose gel electrophoresis as previously described (23).

\section{Construction of plasmids for chromosomal integration into prophage sites}

Plasmid pSA114 is a derivative of plasmid pCS1966 (28) - the chromosomal integration vector, allowing positive selection of cells in which the plasmid had been excised from the genome, resulting in unmarked integrations in the chromosome of L. lactis.

Two DNA fragments 671 and 941bp of adjacent loci of prophage (proPhi1) were amplified from L. lactis TIFN1 chromosome using 1M_HR1_Fw+/1M_HR1_Rv and 1M_HR2_Fw/1M_HR2_1Rv+ primer pairs respectively (see table 1). The two fragments were interconnected by multiple cloning site (MCS) introduced by PCR overlap extension mutagenesis in order to allow further insertions between the homology arms. The resulting $1.7 \mathrm{~Kb}-\mathrm{PCR}$ fragment was digested with $\mathrm{Kpnl}$ and $\mathrm{Ncol}$ and ligated into corresponding sites of pSEUDO-GFP (29) resulting in plasmid pSA114. The 34 bp MCS between the 
amplified prophage sequences of pSA114 was used for further cloning. pSA116, the vector for integration of $\mathrm{CmR}$ (chloramphenicol resistance cassette, cat) into prophage was made by inserting CmR between the prophage homology regions of pSA114. Chloramphenicol cassette (cat) was amplified by PCR using pGhCAM2_Fw/pGhCAM_Rv primers (Table 1) and pVE6007 [pGhost7, (30)] as a template. The fragment was digested with EcoRI and BamHI and sub cloned into corresponding sites of pSA114, yielding pSA116. Plasmid pSA120, the vector for integration of $g f p$ [the gene of the superfolder variant of GFP, (31)] into prophage was made as follows. The gfp flanked by CP25 artificial promoter (32) and two terminator sequences was excised from pIL-JK2 using EcoRI and BamHI and inserted into the same site (between the prophage homology regions) of pSA114, yielding pSA120.

Table 1. Primers used in this study. Restriction enzyme (RE) sites are underlined.

\begin{tabular}{lll}
\hline Name & RE & Nucleotide sequence (5'-3') \\
1M_HR1_Fw+ & MCS & GAATTCCCGGGTCGACAAGCTTAGATCTGGATCCTTGTTGGTTTTGGGCCCATCACTTTA \\
1M_HR1_Rv & Ncol & TTCCATGGGCGCTCCTTCAGGAAAGACGATTA \\
1M_HR2_Fw & Kpnl & TTGGTACCGGCGCTTGGTTATTCTGCTTCTGA \\
1M_HR2_1Rv+ & MCS & GGATCCAGATCTAAGCTTGTCGACCCGGGAATTCTTTGGGTGGCCCATTTCCTACA \\
pGhCAM2_fw & ECORI & AAGAATTCAAGGGGATTTTATGCGTGAGAATG \\
pGhCAM_rv & BgIII/Xhol & ATGGATCCTCGAGATCTGAAAACCCTGGCGTTACCC \\
& /BamHI & \\
& &
\end{tabular}
integration vectors

134 The designed vectors are derivatives of pCS1966 and unable to replicate in L. lactis. The original 135 strategy (28) includes both transformation and chromosomal integration by homologous 136 recombination for the successful acquisition of such vectors by L. lactis cells. Therefore, the plasmid 137 acquisition is drastically dependent on the efficiency of transformation. Industrial "wild" strains are 138 usually featured by poor transformability compared to "domesticated" laboratory L. lactis strains. 139 Therefore, a new strategy has been designed by splitting plasmid transformation and its homologous 140 recombination events. We constructed vectors that combine L. lactis thermosensitive (Ts) replication 141 origin repA $A^{T S}$ and oroP gene. Ts replication origin allows the plasmid replication under permissive 142 temperature after the transformation event, followed by integration through homologous 143 recombination at elevated temperature. Gene oroP enables counterselection for loss of the plasmid 144 backbone, leaving unmarked integrations in the chromosome of L. lactis at specific target sites. 
New vectors, pSA130-YL and pSA132-YL were constructed as follows. E. coli strain EC1000 (33) was used for cloning and plasmid propagation. pG+host9 (30) was used to provide the backbone with repA $A^{T s}$ and ermAM. The plasmids pSA116 and pSA120 were used to provide the cassettes of DNA labels (CmR or sf-gfp) flanked by proPhi1 homology regions (MHR) and oroP. The Kpnl/Fspl fragment of pSA116, was ligated into Kpnl/EcoRV digested pG+host9, resulting in pSA130-YL. pSA132-YL was constructed in two steps: first Kpnl/Sall fragment of pSA120 was ligated into the corresponding site of pG ${ }^{+}$host9, then Sall/Fspl fragment of pSA120 was ligated into Sall/EcoRV site, yielding pSA132-YL.

L. lactis transformation was performed using a modified protocol as we described earlier (23). The confirmed transformants were propagated at the permissive temperature, $28^{\circ} \mathrm{C}$ in $\mathrm{M} 17$ broth $(0.5 \%$ glucose or lactose) with $3 \mathrm{\mu g} / \mathrm{ml}$ erythromycin, and stored in $15 \%$ glycerol at $-80^{\circ} \mathrm{C}$ until further use. For the integration step, L. lactis cells transformed with constructed plasmids were incubated at $37^{\circ} \mathrm{C}$ overnight, the $\mathrm{OD}_{600}$ of cultures was measured, cells were plated in proper dilutions (depending on $\mathrm{OD}_{600}$ values) on selection plates (L/GM17, 1.5\% agar, $0.5 \mathrm{M}$ sucrose and $3 \mu \mathrm{g} / \mathrm{ml}$ erythromycin), and incubated at $37^{\circ} \mathrm{C}$ till colonies emerged. The presence and orientation of the whole plasmid inserts were checked with PCR, and correct validated clones were maintained as $15 \%$ glycerol stocks at $-80^{\circ} \mathrm{C}$.

For the backbone elimination step, the validated clones with integrated plasmids were inoculated in 2 $\mathrm{ml} \mathrm{SA}$ medium (34) containing $1 \%$ lactose or glucose and incubated at $30^{\circ} \mathrm{C}$ overnight. Then they were diluted $10 \mathrm{x}$ in SA (1\% lactose or glucose) medium and incubated $30^{\circ} \mathrm{C}$ for $6 \mathrm{~h}$. Thereafter $10 \mu \mathrm{l}$ of the culture was streaked on SA (1\% lactose or glucose) agar plate supplemented with $10 \mu \mathrm{g} / \mathrm{ml} 5$ fluoroorotate (Sigma). Plates were incubated at $30^{\circ} \mathrm{C}$ until 5-fluoroorotate resistant colonies emerged. For resulting labelled strains, TIFN1::cat and TIFN1::gfp (inserted genes from corresponding plasmiddonors, pSA130-YL and pSA132-YL), correct inserts and their location on TIFN1 chromosome were confirmed by PCR, sequencing the PCR products and phenotypic analysis: either green fluorescence or chloramphenicol resistance.

\section{Phage lipid and DNA labelling}

171 The dyes used for labelling of lipids and DNA are shown in Table 2. To stain DNA, PEG precipitated 172 phage particles were incubated with Sybr Green (Invitrogen, Molecular probes Cat. no. S7563) at $80^{\circ} \mathrm{C}$ 173 for 10 minutes in $10^{-4}$ final dilution of commercial stock as described earlier (35) or with GelRed nucleic 174 acid gel stain (Biotium, $10^{-4}$ final dilution of commercial stock) under the same conditions.

Table 2. Corresponding labelling of lipid and DNA dyes.

Label used in text Name of the dye




\begin{tabular}{ll} 
Lipophilic dye 1 & FM 4-64 \\
Lipophilic dye 2 & MitoTracker Green FM \\
\hline Lipophilic dye 3 & CellMask Deep Red \\
DNA dye 1 & Sybr Green \\
\hline DNA dye 2 & GelRed Nucleic Acid Gel stain \\
\hline
\end{tabular}

177 For membrane detection CellMask DeepRed (Life Technologies $\mathrm{GmbH}$ ) was used in final dilution $10^{-3}$ 178 of commercial stock and phages were incubated for 5 minutes at $37^{\circ} \mathrm{C}$; FM4-64 (Molecular Probes) 179 was used in a final concentration $20 \mu \mathrm{g} / \mathrm{ml}$, incubation proceeded 15 minutes at room temperature; 180 and MitoTracker Green FM (Molecular Probes Cat. no. M7514) was used at final concentration of 20 $181 \mathrm{nM}$ and phages were incubated with the dye for 15 minutes at $37^{\circ} \mathrm{C}$. For double staining of DNA and 182 membrane, MitoTracker was added to the phages stained with GelRed, the samples were vortexed 183 and measured immediately by flow cytometry. In control experiment the membranes were first 184 extracted by adding to the phage suspension equal volumes of chloroform, the samples were vortexed, centrifuged during 3 minutes at $14000 \times \mathrm{g}$, aqueous phase containing the phage particles was collected and the staining was performed as described above.

When phages were not added, no detectable fluorescent particles were present in the control samples. To exclude contamination of phage suspension by bacterial cells, bacteria were added to phage suspension prior to staining of either DNA or lipids. In these control samples an additional population of particles with much higher fluorescence intensity was detected (not shown), as anticipated, given a bacterial cell contains much higher amounts of lipids and DNA per particle compared to phages.

\section{Flow Cytometry}

Prior to flow cytometry analysis $2 \mu$ l of fluorescent microspheres $\left(1 \times 10^{-3}\right.$ of the stock Fluoresbrite ${ }^{\circledR}$ YG Microspheres $0.75 \mu \mathrm{m}$, Polysciences) was added and the volume was adjusted to $500 \mu \mathrm{l}$ by adding FACSFlow solution (10 mM phosphate-buffered saline, $150 \mathrm{mM} \mathrm{NaCl}$, pH 7.4; Becton-Dickinson). Samples were analyzed by using a BD FACS Aria ${ }^{\mathrm{TM}}$ III flow cytometer (BD Biosciences, San Jose, CA). The cytometer was set up using an $85 \mu \mathrm{m}$ nozzle and was calibrated daily using BD FACSDiva Cytometer Setup and Tracking (CS\&T) software and CS\&T Beads (BD Biosciences). An $488 \mathrm{~nm}$, air-cooled argonion laser and the photomultipliers with $488 / 10$ band pass filter for forward and side scatter and with filter 530/30 nm (with 502 LP filter) was used for the detection of GFP, Sybr Green and MitoTracker. GelRed was excited with a yellow-green $561 \mathrm{~nm}$ laser and detected using a 610/20 nm with LP $600 \mathrm{~nm}$ 
dye was excited with $561 \mathrm{~nm}$ laser and detected with a 780/60 nm with LP $735 \mathrm{~nm}$ filter. FSC and SSC voltages of 300 and 350, respectively, and a threshold of 1,200 on FSC was applied to gate on the bacteriophages and bacterial cells population.

Data were acquired by using BD FACSDiva ${ }^{\mathrm{TM}}$ software and analyzed by using FlowJo flow cytometry analysis software (Tree Star, Ashland, OR).

\section{Chemical lipid analysis}

209 Normal phase high performance liquid chromatography (NP-HPLC) with evaporative light scattering 210 detection (ELSD) was used for the quantitative analysis of phospholipids (36).

211 The analyses were performed with a 600E System Controller (Waters), vacuum degasser (Knauer), 231

212 XL sampling injector (Gilson) and a 3300 (ELSD) evaporative light scattering detector (Alltech).

213 Extraction of the phospholipids from $2 \mathrm{~g}$ freeze dried milk sample was done with a mixture of 214 chloroform, methanol and ammonia $\left(\mathrm{NH}_{3}\right)$ in water. After centrifugation of the sample $10 \mathrm{~min}$ at 4500

$215 \mathrm{~g}, 10.0 \mathrm{~mL}$ of the supernatant was evaporated under vacuum at $40^{\circ} \mathrm{C}$ in a heating block. When the 216 sample was dried, $1 \mathrm{~mL}$ absolute ethanol was added and again evaporated to dryness. The dried 217 sample was dissolved in $1.0 \mathrm{~mL}$ of the phospholipid solvent containing iso-octane, chloroform and 218 methanol.

219 Fifty milliliter of the sample solution was injected on an Xbridge amide analytical column, $3.5 \mu \mathrm{m}, 4.6$ $220 \times 250 \mathrm{~mm}$ (Waters). The components were eluted at a flow rate of $1.0 \mathrm{~mL} / \mathrm{min}$ with a gradient of eluent 221 A (iso-octane and acetone) and eluent B (2-propanol and ethyl acetate) to eluent C (2-propanol, water, 222 ammonia and acetic acid) in 50 minutes. Data analysis was done with Chromeleon software version 2237.2 (Thermo Fisher Scientific). The non-linear response of the ELSD was converted to a more linear 224 signal in order to increase the accuracy of the quantification of phospholipids differing in fatty acid 225 composition compared to those of the standard.

226 1,2-dipalmitoyl-sn-glycero-3-phosphoryl ethanolamine (PE, Matreya), 1,2-dipalmitoyl-sn-glycero-3227 phosphoryl glycerol (PG, Matreya), 3-sn-lyso phosphatidyl ethanolamine (LPE, Sigma), DL- $\alpha$ 228 phosphatidyl choline (dipalmitoyl, C16:0) (PC, Sigma), Sphingomyelin (SM, Sigma), phosphatidyl serine 229 (oleoyl) (PS, Matreya), lyso-phosphatidylcholine (palmitoyl) (LPC, Matreya) and phosphatydyl inositol 230 (linoleoyl) (PI, Matreya) were used as calibration standards for quantitative analysis. A reference 231 sample (buttermilk powder) with known amounts of phospholipids was analyzed and recovery of 232 spiked phospholipids was performed to control for accuracy and precision of the method.

\section{Scanning/transmission electron microscopy}


234 For scanning electron microscopy, L. lactis TIFN1 and TI1c cultures were subjected to $1 \mu \mathrm{g} / \mathrm{ml}$ MitC 235 induction as described above. After $5 \mathrm{~h}$ of induction the samples were fixed with $2.5 \%$ glutaraldehyde in PBS buffer for 1 hour at room temperature. A droplet of the fixed cell suspension was placed onto poly-L-lysine coated coverslips (Corning BioCoat, USA) and allowed to stand for 1 hour at room temperature. After rinsing in PBS the samples were post stained in $1 \%$ osmium tetroxide in PBS. Subsequently the samples were dehydrated in a graded series of ethanol followed by critical point drying with $\mathrm{CO}_{2}$ (Leica EM CPD300, Leica Microsystems). The coverslips were fitted onto sample stubs using carbon adhesive tabs and sputter coated with $6 \mathrm{~nm}$ Iridium (Leica SCD500). Samples were imaged at $2 \mathrm{KV}, 6 \mathrm{pA}$, at room temperature in a field emission scanning electron microscope (Magellan 400, FEl Company, Oregon, USA).

For transmission electron microscopy, purified phage particles were subjected to negative staining and examined exactly as descried previously (23).

\section{Results}

\section{No detectable cell lysis during phage release}

A previous study on Lactococcus lactis strains TIFN1-7 originating from the mixed cheese starter culture indicated no obvious drop in the optical density of the bacterial cultures following prophage activation (23). We were triggered by this observation and therefore we further examined this phenomenon using strain TIFN1 as a model. We first analyzed the cell viability in prophage induced cultures supplemented with mitomycin C (MitC) and control cultures without MitC induction. The total cell counts determined using a haemocytometer and the number of culturable cells, i.e., colony forming units, were similar (supplementary Fig. S1), indicating that at least the vast majority of TIFN1 cells present in the tested conditions remained viable. Both cell counting methods showed no obvious differences in cell numbers from the prophage-induced cultures and non-induced control cultures, further confirming that in the L. lactis strains, represented by lysogen TIFN1, there was no detectable cell lysis in spite of the abundant phage release upon phage induction.

\section{The major part of the culture actively produces phages}

262 To elucidate whether phage production is a population-wide activity in a clonal culture of strain TIFN1, 263 we monitored in vivo phage replication using a reporter strain, in which a gfp reporter was inserted within the prophage. In cells actively replicating the phage particles, green fluorescence intensity was expected to increase. As mentioned, we used L. lactis TIFN1 as the model strain, which harbors the 
genome of prophage proPhi1 (6). The insertion site was selected within the prophage sequence between stop codons of open reading frames (ORFs) 48 and 49 encoded on opposite DNA strands (Fig. 1A), resulting in strain TIFN1::gfp. In parallel, a fluorescence-negative control strain was constructed in which the chloramphenicol resistance gene cat was inserted at the same site, yielding strain TIFN1::cat.

The derived strain TIFN1::gfp showed similar growth behavior (Fig. 1B) to the wild-type TIFN1 (data see Alexeeva et al., 2018) with and without prophage induction by MitC, as indicated by monitoring culture turbidity. TIFN1::gfp also produced phage particles (Fig. 1C) to a similar amount as the wildtype (data see Alexeeva et al., 2018): $10^{10}$ phage particles $/ \mathrm{mL}$ were found in cultures without added MitC and phage numbers increased to $\sim 10^{11} / \mathrm{ml}$ upon MitC induction in $6 \mathrm{~h}$, as estimated by quantifying phage DNA content.

To study the in vivo dynamics of prophage induction in L. lactis TIFN1 we used strain TIFN1::gfp and followed in time the fluorescence intensity of the cells by flow cytometry in MitC-induced and uninduced cultures. As a fluorescence-negative control we used TIFN1::cat. TIFN1::cat exhibited very low background fluorescence, not changing in time and not affected by MitC addition (Fig. 1D). The uninduced culture of TIFN1::gfp showed moderate fluorescence already at the initiation of induction (time point $0 \mathrm{~h}$ ), and the fluorescence increased slightly in time. This is in line with the observed constitutive phage induction and replication taking place even without MitC induction (Fig. 1C and Fig. 1D). The induced culture of TIFN1::gfp showed a clear increase in fluorescence intensity till the $4^{\text {th }}$ hour post-induction, and then the fluorescence intensity declined slightly. The increase in fluorescence intensity of the cells was 2.5-3 fold and correlated with the increase in the number of released phage particles (Fig. 1C and Fig. 1D).

288 To examine whether the major fraction of the bacterial population actively produces phage particles,

289 the distribution of fluorescence in individual cells was measured by flow cytometry. The fluorescence distribution per particle in the negative control (TIFN1::cat, black unfilled) as well as in un-induced cultures of TIFN1::gfp (grey unfilled) and MitC induced TIFN1::gfp (green filled) at time point 3 hours post-induction was measured (Fig. 1E). In the MitC induced TIFN1::gfp culture more than $80 \%$ of the cells are green fluorescent and more than $60 \%$ are highly fluorescent, which is a distinct population

294 (second green peak in Fig. 1E). This indicates that the majority of the cells in the population actively replicate phage DNA and produce phage proteins. When relating this observation to the cell count results (supplementary Fig. S1), where no obvious reduction in cell number was detected under phage inducing conditions, the hypothesis of non-lytic phage release is supported. 


\section{Phages are enclosed in lipid bilayers}

300 Non-lytic, chronic phage release has been previously described to occur via budding (Plasmaviridae) 301 or extrusion (Inoviridae) (17-20). In case the budding mechanism of cell exit is recruited by the phage 302 particles, it is expected to be enveloped by cellular lipids upon release. Therefore, first of all, we analyzed the presence of a lipid bilayer in/engulfing the phage particles. We employed three lipophilic dyes staining cellular membranes/lipid bilayers, but all essentially non-fluorescent in aqueous media. All three lipophilic dyes were efficiently staining the phage particles (Fig. 2A-C), confirming presence of lipid membranes. Moreover, when the phage particles were treated with chloroform prior to staining with lipophilic dye 3, the fluorescence was largely abolished (Fig. 2C, blue line). The chloroform treated particles were visualized by EM and showed typical morphology of phage heads (see Fig. 1A \& B from Alexeeva et al., 2018). We further confirmed that the lipid enclosed particles are indeed bacteriophages containing DNA: the phage particles were readily stained with the two DNA dyes (Fig. 2D \& E). Moreover, double staining with DNA dye 2 (red fluorescence) in combination with lipophilic dye 2 (membrane stain, green fluorescence) resulted in double stained particles, confirming that the phage particles indeed contain DNA and are enclosed by membranes (Fig. 2F). This conclusion is also supported by the previous study where the tailless phage particles were isolated with the same method and subjected to DNA sequencing, and full phage genomes were recovered with more than 100 -fold higher coverage than background (6).

317 Since the hypothesis of phage particles being enclosed in lipid bilayer is now supported by 318 experimental evidence, we continued to find additional support by studying the phage particles with 319 transmission electron microscopy (TEM). In this case, phage particles were not pre-treated with 320 chloroform to retain the lipid membrane, and we compared the particle morphology and size to chloroform-treated phage particles. It was observed that the morphology of untreated (Fig. 3A) and chloroform-treated (Fig. 3B) particles was similar, although they did show different electron-densities as reflected by the different darkness of particles, possibly indicating differences in compositions as chloroform will disintegrate lipid bilayers and dissolve lipids. We also noticed a difference in particle sizes caused by chloroform treatment. When measuring the particle diameters (defined as the distance between two opposite corners of the hexagon shape, measured by ObjectJ), untreated particles showed diameters of $65.4 \pm 4.1 \mathrm{~nm}(\mathrm{n}=54)$, significantly ( $p<0.00001$, 2-tailed, unequal variance) larger than chloroform-treated particles with diameters $58.0 \pm 2.0 \mathrm{~nm}(\mathrm{n}=27)$. The difference in average diameters, $7.4 \pm 4.6 \mathrm{~nm}$, coincides with the thickness of two lipid bilayers (37). This analysis also supports the hypothesis that the released phage particles of L. lactis TIFN1 are enclosed in lipid bilayers. 


\section{Lipid composition of phage particles differs from host cells}

334 Next, we extracted the lipids from phage crops produced by strain TIFN1 and also from whole cell335 derived protoplasts and subjected them to chemical lipid analysis using liquid chromatography coupled 336 with mass spectrometry (LS-MS). As a phage-free control, phage-cured strain TI1c (23) was subjected to the same procedure of prophage induction and purification from the culture supernatant. The TIFN1 phage specimen lipid signals were well above the background level of the phage-free control from TI1c (supplementary Fig. S2). Phosphatidyl glycerol (PG) and cardiolipin (CA) were detected in phage samples as well as in cellular lipid samples, however, the ratio between the two major lipid species differed between the phage and the cell membrane lipid samples (Fig. 4).

The major lipid in the L. lactis cell membrane is cardiolipin and a CA/PG ratio of about 2.2 has been determined for L. lactis membrane earlier (38). We found the CA/PG ratio value of 1.5 for cellular lipids extracted from TIFN1 (Fig. 4B). Remarkably, lipids of the phage crops were enriched in phosphatidyl glycerol with a CA/PG ratio of 0.4 (Fig. 4A). This suggests that the released phage particles are possibly enclosed by phospholipids derived from distinct regions of lipid rafts/domains in the L. lactis cell membrane $(39,40)$.

To further characterize the phage release from the cells we employed scanning electron microscopy to observe MitC induced cells of wild-type strain TIFN1 and its prophage cured derivative strain TI1C (Fig. 5). The MitC treated TI1c had the usual morphology and smooth surface of a Gram-positive coccus without any detectable alteration (Fig. 5C \& D). Strain TIFN1 however, showed a ruffled cell surface and accumulated numerous budlike, small spherical structures, typically near the cell division septum (Fig. 5A \& B). The phage cured strain TI1c lacked these extracellular structures.

The observation that extracellular particles are accumulated near the cell division planes is in line with our speculation made from the observation of a difference in lipid composition between phage particles and the host cells indicating that the processes of phage engulfing and release are specific for defined regions of the cell membrane.

\section{Discussion}

360 Bacteriophages are thought to be the most abundant biological entities on Earth and adopted a striking variety of forms and mechanisms of interaction with their host cells (41). Combining observations from this study, we propose a novel mechanism of interaction for lactococcal phages and their hosts, where the tailless Siphoviridae phage particles are enclosed in a lipid membrane and are released from the 
cells by a non-lytic mechanism (Fig. 6). This chronic, non-lytic phage release mechanism has not been previously described for LAB phages or Siphoviridae phages.

The prophage found in L. lactis TIFN1, referred to as proPhi1, is classified in the family of Siphoviridae, which members are by definition tailed bacteriophages. Genomic analysis also revealed that genes encoding tail structures are present in these prophages, but due to disruptions in some of the tail genes, the assembled phage particles show a tailless phenotype (6). Interestingly, the lipid-containing phages discovered so far, mostly assigned to families of Corticoviridae, Cystoviridae, Plasmaviridae and Tectiviridae, are exclusively tailless phages (42). Plausibly, the reason that the membrane-containing feature was not found in any tailed phages is that they already achieve successful infection with the help of the tail device that efficiently penetrates the cell envelop, and no alternative infection mechanism was required (42). Tailless phages, on the other hand, are evolved to utilize the membrane to infect or interact with their hosts. For example, enveloped phages use a membrane fusion mechanism to interact with the host and deliver their genetic materials (42-45). Therefore, it was part of the hypothesis that the tailless proPhi1 being enclosed in a lipid membrane could serve as an alternative infection strategy as the tail device is not available anymore, but so far we did not obtain evidence demonstrating the (re)infection of host by the membrane-enclosed tailless phage particles (data not shown). It remains to be investigated whether the hurdle was for membrane-enclosed phage particles to attach and enter the host, or rather for the tailless phage particles to inject their genetic material into the bacterial cytoplasm to complete the life cycle.

In previously described membrane-enclosed phages, the mechanism of incorporation of lipids to form virus-specific vesicles has been subjected to investigation. However, not everything is completely understood until today, but several mechanisms are proposed (42). For one, phage encoded membrane proteins trigger cytoplasmic membrane formation in the host, and enclose the phages during assembly in the cell. For example, Cystoviridae phage phi6 applies a mechanism, in which the protein P9 was found to facilitate cytoplasmic membrane formation in bacteria (46). Host-derived membrane components can be an alternative mechanism. In this case, phage-encoded membrane proteins are incorporated into the host membrane, providing a scaffold for phage assembly, and the assembled phage particles are released upon lysis of the host $(47,48)$. Examples are Tectiviridae phage PRD1 employing membrane protein P10 (49), and Corticoviridae phage PM2 employing membrane proteins P3 and P6 to interact with phage-specific areas on the cell membrane $(42,50)$. For all above mentioned phage-encoded proteins, we did not find homology to any of the proteins encoded on proPhi1 or any of the other prophages found in lactococci isolated from the starter culture Ur (6). However, it should be noted that other membrane-associated protein coding sequences were indeed predicted in the Ur prophages, namely ORF42 in proPhi1\&5, ORF08 in proPhi2\&4 and ORF49 in proPhi6 
398 (6). Targeting phage particles to special areas of cell membrane by membrane-associated proteins 399 could potentially be an explanation for the distinct lipid composition associated with released phage particles. Nevertheless, non-lytic release via a mechanism of budding is still not confirmed in other phages but suggested for plasmavirus (19) and is considered a very delicate life cycle of viruses, as it leaves the host alive while phages get to spread the progeny (42). Whether the non-lytic release of membrane-enclosed phages in L. lactis TIFN1 and other lactococcal strains found in the starter culture Ur is a result of long-term phage-host co-evolution thus becomes an even more interesting hypothesis, especially as we observed similar growth behavior during phage release in other Ur strains (23).

Another intriguing question is how the membrane-enclosed phage particles escape from the bacterial host without lysis, especially given the fact that L. lactis is Gram-positive, possessing thick cell wall outside the cell membrane. A similar question has been raised for extracellular membrane vesicles (MVs or EVs) produced by Gram-positive bacteria ever since the discovery of such phenomenon. It has already been known for a long time that Archaea, Gram-negative bacteria, and mammalian cells actively secrete the nano-sized, lipid bilayer-enclosed particles named EVs, harboring various nucleotide and protein cargos as a mechanism for cell-free intercellular interactions (51-53). Only recently, evidence was provided that EVs are also released by organisms with thick cell walls like Grampositive bacteria, mycobacteria and fungi (54-57), but the mechanistic insights are still lacking. Brown et al. (2015) proposed several non-mutually exclusive mechanisms on the formation and release of EVs through thick cell walls, including the actions of turgor pressure, cell wall-modifying enzymes and protein channels. The most evidence-supported mechanism is via cell-wall modifying enzymes, namely autolysin (58) and prophage-encoded holin-endolysin $(59,60)$. Notably, phage particles have also been identified as part of the cargos in EVs produced by Bacillus subtilis (59). Further studies dedicated to elucidating the roles of autolysin and/or phage-encoded holin-endolysin in L. lactis TIFN1 would serve to reveal the release mechanism in this case.

Moreover, the effect of turgor pressure could also play a role in addition (57). It is plausible that upon prophage induction, the defective proPhi1 particles are abundantly assembled and accumulated in the cells, causing cytoplasmic crowding that results in elevated turgor pressure. The cell division site is often the target site of autolysins (61), in combination with induced phage-encoded endolysins, forming the weakest spot on the cell and giving opportunities for the phage particles to release under turgor pressure, which could explain our observation that the membrane-enclosed particles are mostly observed near the cell division sites, and have a distinct lipid profile comparing the whole cell samples. Therefore, we propose that the phenomenon of non-lytic membrane engulfed phage release observed 
the cell envelope, in combination with phage-encoded proteins to achieve phage-specific engulfment and release.

Although this is the first study to demonstrate non-lytic release of membrane-engulfed phages in LAB, we would like to point out that this could be a more common but up to now overlooked phenomenon in other microbial communities for two reasons. Firstly, studies focused on the detection of inducible prophages, use cell lysis/plaque formation as a benchmark for phage activation. Obviously, when (tailless) phage particles are released via membrane envelops or other non-lytic ways, no apparent phenotype will be observed thus discouraging further investigation. Secondly, it is a common practice in phage isolation protocol to employ chloroform to remove contaminating materials derived from bacterial cells (42), however, this treatment demolishes the membrane structures and therefore the lipid-containing phenotype is conceivably not retrieved in further analysis of phage particles. We hope that our findings will inspire further studies, not only in elucidating the detailed mechanism of this case, but also in awareness and discovery of similar phenomena in other microbial species, and further shedding light on bacteria-phage interaction and co-evolution.

\section{Data availability statement}

The datasets used and/or analyzed during the current study are available from the corresponding author on reasonable request.

\section{Authors' contributions}

SA and EJS conceived the study. SA, EJS and YL designed the experiments. YL and SA executed the experiments and carried out the data analysis and interpretation. HB was involved in the chemical lipid analysis, JAGM prepared samples for electron microscopy and obtained the pictures. NY and SA did the fluorescent lipid detection. YL, SA, TA and EJS wrote the manuscript.

All authors read and approved the final manuscript.

\section{Funding}

This study was financed by Top Institute Food and Nutrition (TIFN) in Wageningen, the Netherlands. In addition, YL was subsidized by the Netherlands Organisation for Scientific Research (NWO) through the Graduate Program on Food Structure, Digestion and Health. 


\section{Conflict of interest}

463 Author Herwig Bachmann was employed by the company NIZO B.V. The remaining authors declare 464 that the research was conducted in the absence of any commercial or financial relationships that could 465 be construed as a potential conflict of interest.

\section{Acknowledgments}

We thank Lieke Gijtenbeek and Jan Kok (RUG) for providing plasmids pCS1966, pVE6007, and pSEUDOGFP. Emmanuelle Maguin (INRA, France) is acknowledged for providing pG'host9. The authors cordially thank Guido Staring (NIZO food research, Ede, the Netherlands) for performing LC-MS/ESI lipid analysis. The electron microscopy images were obtained with the help of Marcel Giesbers at the Wageningen Electron Microscopy Centre (WEMC) of Wageningen University (Wageningen, The Netherlands).

\section{References}

478 1. Clokie MRJ, Millard AD, Letarov A V., Heaphy S. 2011. Phages in nature. Bacteriophage 1:31-45.

479 2. Hatfull GF, Hendrix RW. 2011. Bacteriophages and their genomes. Curr Opin Virol 1:298-303.

480 3. Ackermann H-W. 2009. Phage classification and characterization. Methods Mol Biol 501:127-140.

481 4. Krupovic M, Prangishvili D, Hendrix RW, Bamford DH. 2011. Genomics of bacterial and archaeal viruses: dynamics within the prokaryotic virosphere. Microbiol Mol Biol Rev 75:610-35.

5. Parmar KM, Gaikwad SL, Dhakephalkar PK, Kothari R, Singh RP. 2017. Intriguing interaction of bacteriophage-host association: an understanding in the era of omics. Front Microbiol 8:559.

6. Alexeeva S, Liu Y, Zhu J, Kaczorowska J, Kouwen TRHM, Abee T, Smid EJ. 2021. Genomics of tailless bacteriophages in a complex lactic acid bacteria starter culture. Int Dairy J 114:104900.

7. Ackermann H-W. 2007. 5500 Phages examined in the electron microscope. Arch Virol 152:227-243.

8. McGrath S, Neve H, Seegers JFML, Eijlander R, Vegge CS, Brøndsted L, Heller KJ, Fitzgerald GF, Vogensen FK, van Sinderen D. 2006. Anatomy of a Lactococcal phage tail. J Bacteriol 188:3972-82.

9. Legrand P, Collins B, Blangy S, Murphy J, Spinelli S, Gutierrez C, Richet N, Kellenberger C, Desmyter A, Mahony J, van Sinderen D, Cambillau C. 2016. The atomic structure of the phage Tuc2009 baseplate tripod suggests that host recognition involves two different carbohydrate binding modules. MBio 7:e01781-15.

10. Howard-Varona C, Hargreaves KR, Abedon ST, Sullivan MB. 2017. Lysogeny in nature: mechanisms, impact and ecology of temperate phages. ISME J 11:1511-1520. 
11. Pleška M, Lang M, Refardt D, Levin BR, Guet CC. 2018. Phage-host population dynamics promotes prophage acquisition in bacteria with innate immunity. Nat Ecol Evol 2:359-366.

12. Erez Z, Steinberger-Levy I, Shamir M, Doron S, Stokar-Avihail A, Peleg Y, Melamed S, Leavitt A, Savidor A, Albeck S, Amitai G, Sorek R. 2017. Communication between viruses guides lysis-lysogeny decisions. Nature 541:488-493.

13. Dou C, Xiong J, Gu Y, Yin K, Wang J, Hu Y, Zhou D, Fu X, Qi S, Zhu X, Yao S, Xu H, Nie C, Liang Z, Yang S, Wei $Y$, Cheng W. 2018. Structural and functional insights into the regulation of the lysis-lysogeny decision in viral communities. Nat Microbiol 3:1285-1294.

14. Gowen B, Bamford JKH, Bamford DH, Fuller SD. 2003. The tailless icosahedral membrane virus PRD1 localizes the proteins involved in genome packaging and injection at a unique vertex. J Virol 77:786371.

15. Poranen MM, Domanska A. 2009. Virus entry to bacterial cells, p. 365-370. In van Regenmortel, MHV, Mahy, BWJ (eds.), Desk encyclopedia of general virology, 1st ed. Academic Press.

16. Sun Y, Roznowski AP, Tokuda JM, Klose T, Mauney A, Pollack L, Fane BA, Rossmann MG. 2017. Acad Sci U S A 114:13708-13713.

512 17. Russel M. 1991. Filamentous phage assembly. Mol Microbiol 5:1607-13.

18. Marvin DA, Symmons MF, Straus SK. 2014. Structure and assembly of filamentous bacteriophages. Prog Biophys Mol Biol 114:80-122.

19. Putzrath RM, Maniloff J. 1977. Growth of an enveloped mycoplasmavirus and establishment of a carrier state. J Virol 22:308-314.

20. Krupovic M, ICTV Report Consortium. 2018. ICTV virus taxonomy profile: Plasmaviridae. J Gen Virol 99:617-618.

21. Hobbs Z, Abedon ST. 2016. Diversity of phage infection types and associated terminology: the problem with 'Lytic or lysogenic.' FEMS Microbiol Lett 363:fnw047.

22. Oksanen HM, Poranen MM, Bamford DH. 2010. Bacteriophages: Lipid-containingEncyclopedia of Life Sciences. John Wiley \& Sons, Ltd, Chichester, UK.

23. Alexeeva S, Guerra Martínez JA, Spus M, Smid EJ. 2018. Spontaneously induced prophages are abundant in a naturally evolved bacterial starter culture and deliver competitive advantage to the host. BMC Microbiol 18:120.

24. Lavigne R, Molineux IJ, Kropinski AM. 2012. Order - Caudovirales, p. 39-45. In King, AMQ, Adams, MJ, Carstens, EB, Lefkowitz, EJ (eds.), Virus Taxonomy: Ninth Report of the International Committee on Taxonomy of Viruses. Elsevier.

25. Fu Y, Wu Y, Yuan Y, Gao M. 2019. Prevalence and diversity analysis of candidate prophages to provide an understanding on their roles in Bacillus thuringiensis. Viruses 11:388.

26. Zhu W, Wang J, Zhu Y, Tang B, Zhang Y, He P, Zhang Y, Liu B, Guo X, Zhao G, Qin J. 2015. Identification of three extra-chromosomal replicons in Leptospira pathogenic strain and development of new shuttle vectors. BMC Genomics 16:90.

27. Hertel R, Rodríguez DP, Hollensteiner J, Dietrich S, Leimbach A, Hoppert M, Liesegang $\mathrm{H}$, Volland $\mathrm{S}$. 2015. Genome-based identification of active prophage regions by next generation sequencing in Bacillus licheniformis DSM13. PLoS One 10:e0120759.

28. Solem C, Defoor E, Jensen PR, Martinussen J. 2008. Plasmid pCS1966, a new selection/counterselection tool for lactic acid bacterium strain construction based on the oroP gene, encoding an orotate transporter from Lactococcus lactis. Appl Environ Microbiol 74:4772-4775.

29. Pinto JPC, Zeyniyev A, Karsens H, Trip H, Lolkema JS, Kuipers OP, Kok J. 2011. pSEUDO, a genetic integration standard for Lactococcus lactis. Appl Environ Microbiol 77:6687-6690. 
31. Pédelacq J-D, Cabantous S, Tran T, Terwilliger TC, Waldo GS. 2006. Engineering and characterization of a superfolder green fluorescent protein. Nat Biotechnol 24:79-88.

32. Jensen PR, Hammer K. 1998. The sequence of spacers between the consensus sequences modulates the strength of prokaryotic promoters. Appl Environ Microbiol 64:82-87.

33. Leenhouts K, Venema G, Kok J. 1998. A lactococcal pWV01-based integration toolbox for bacteria. Methods Cell Sci 20:35-50.

34. Jensen PR, Hammer K. 1993. Minimal requirements for exponential growth of Lactococcus lactis. Appl Environ Microbiol 59:4363-6.

35. Brussaard CPD. 2009. Enumeration of bacteriophages using flow cytometry. Methods Mol Biol 501:97111.

36. Christie WW, Noble RC, Davies G. 1987. Phospholipids in milk and dairy products. Int J Dairy Technol

37. Mitra K, Ubarretxena-Belandia I, Taguchi T, Warren G, Engelman DM. 2004. Modulation of the bilayer thickness of exocytic pathway membranes by membrane proteins rather than cholesterol. Proc Natl Acad Sci U S A 101:4083-4088.

38. Driessen AJM, Zheng T, In't Veld G, Op den Kamp JAF, Konings WN. 1988. Lipid requirement of the branched-chain amino acid transport system of Streptococcus cremoris. Biochemistry 27:865-872.

39. Epand RM, Epand RF. 2009. Domains in bacterial membranes and the action of antimicrobial agents. Mol Biosyst 5:580-587.

40. Matsumoto K, Kusaka J, Nishibori A, Hara H. 2006. Lipid domains in bacterial membranes. Mol Microbiol 61:1110-1117.

41. Keen EC. 2015. A century of phage research: bacteriophages and the shaping of modern biology. BioEssays 37:6-9.

42. Mäntynen S, Sundberg LR, Oksanen HM, Poranen MM. 2019. Half a century of research on membranecontaining bacteriophages: bringing new concepts to modern virology. Viruses 11:76.

45. Harrison SC. 2015. Viral membrane fusion. Virology 479-480:498-507.

46. Lyytinen OL, Starkova D, Poranen MM. 2019. Microbial production of lipid-protein vesicles using enveloped bacteriophage phi6. Microb Cell Fact 18:29.

47. Rydman PS, Bamford DH. 2003. Identification and mutational analysis of bacteriophage PRD1 holin protein P35. J Bacteriol 185:3795-3803.

48. Krupovič M, Daugelavičius R, Bamford DH. 2007. A novel lysis system in PM2, a lipid-containing marine double-stranded DNA bacteriophage. Mol Microbiol 64:1635-1648.

49. Mindich L, Bamford D, McGraw T, Mackenzie G. 1982. Assembly of bacteriophage PRD1: particle formation with wild-type and mutant viruses. J Virol 44:1021-1030.

50. Abrescia NGA, Grimes JM, Kivelä HM, Assenberg R, Sutton GC, Butcher SJ, Bamford JKH, Bamford DH, Stuart DI. 2008. Insights into virus evolution and membrane biogenesis from the structure of the marine lipid-containing bacteriophage PM2. Mol Cell 31:749-761.

51. Deatherage BL, Cookson BT. 2012. Membrane vesicle release in bacteria, eukaryotes, and archaea: A conserved yet underappreciated aspect of microbial life. Infect Immun 80:1948-1957.

52. Mashburn-Warren LM, Whiteley M. 2006. Special delivery: vesicle trafficking in prokaryotes. Mol Microbiol 61:839-846. 
53. Schwechheimer C, Kuehn MJ. 2015. Outer-membrane vesicles from Gram-negative bacteria: biogenesis and functions. Nat Rev Microbiol 13:605-619.

54. Rodrigues ML, Nimrichter L, Oliveira DL, Frases S, Miranda K, Zaragoza O, Alvarez M, Nakouzi A, Feldmesser M, Casadevall A. 2007. Vesicular polysaccharide export in Cryptococcus neoformans is a eukaryotic solution to the problem of fungal trans-cell wall transport. Eukaryot Cell 6:48-59.

55. Marsollier L, Brodin P, Jackson M, Korduláková J, Tafelmeyer P, Carbonnelle E, Aubry J, Milon G, Legras P, André J-P Saint, Leroy C, Cottin J, Guillou ML, Reysset G, Cole ST. 2007. Impact of Mycobacterium ulcerans Biofilm on Transmissibility to Ecological Niches and Buruli Ulcer Pathogenesis. PLoS Pathog 3:e62.

56. Lee E-Y, Choi D-Y, Kim D-K, Kim J-W, Park JO, Kim S, Kim S-H, Desiderio DM, Kim Y-K, Kim K-P, Gho YS. 2009. Gram-positive bacteria produce membrane vesicles: proteomics-based characterization of Staphylococcus aureus-derived membrane vesicles. Proteomics 9:5425-5436.

57. Brown L, Wolf JM, Prados-Rosales R, Casadevall A. 2015. Through the wall: extracellular vesicles in

58. Wang X, Thompson CD, Weidenmaier C, Lee JC. 2018. Release of Staphylococcus aureus extracellular

59. Toyofuku M, Cárcamo-Oyarce G, Yamamoto T, Eisenstein F, Hsiao CC, Kurosawa M, Gademann K, Pilhofer M, Nomura N, Eberl L. 2017. Prophage-triggered membrane vesicle formation through peptidoglycan damage in Bacillus subtilis. Nat Commun 8:481.

60. Andreoni F, Toyofuku M, Menzi C, Kalawong R, Shambat SM, François P, Zinkernagel AS, Eberl L. 2019. Antibiotics stimulate formation of vesicles in staphylococcus aureus in both phage-dependent and independent fashions and via different routes. Antimicrob Agents Chemother 63:e01439-18.

61. Vermassen A, Leroy S, Talon R, Provot C, Popowska M, Desvaux M. 2019. Cell wall hydrolases in bacteria: Insight on the diversity of cell wall amidases, glycosidases and peptidases toward peptidoglycan. Front Microbiol 10:331. 
A.

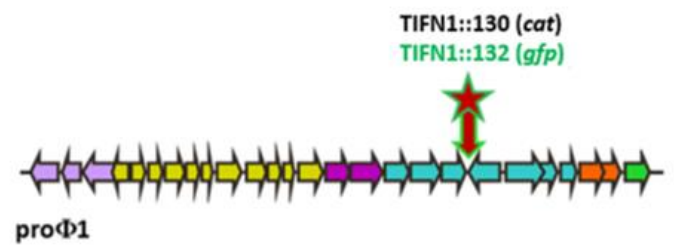

B.

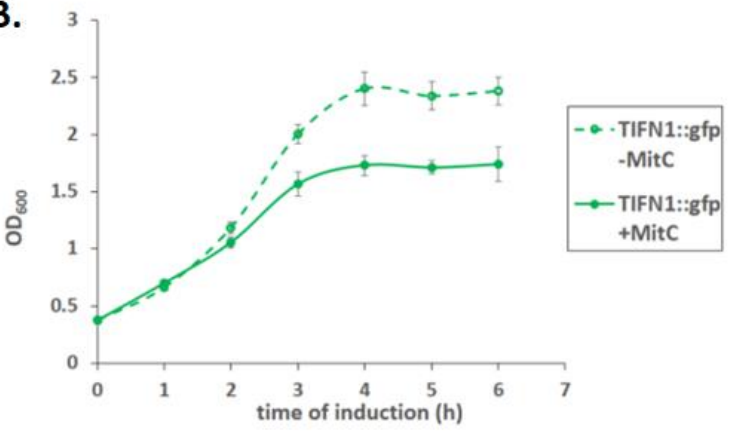

D.

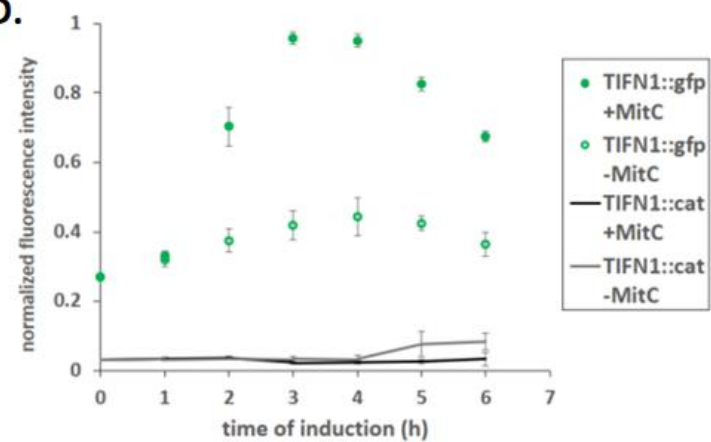

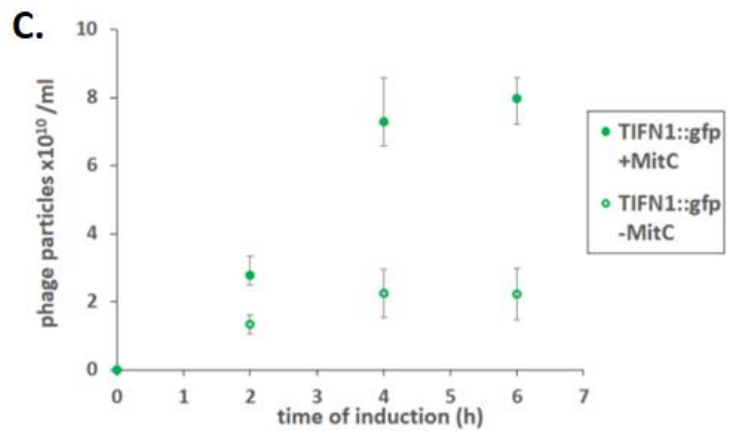

E.

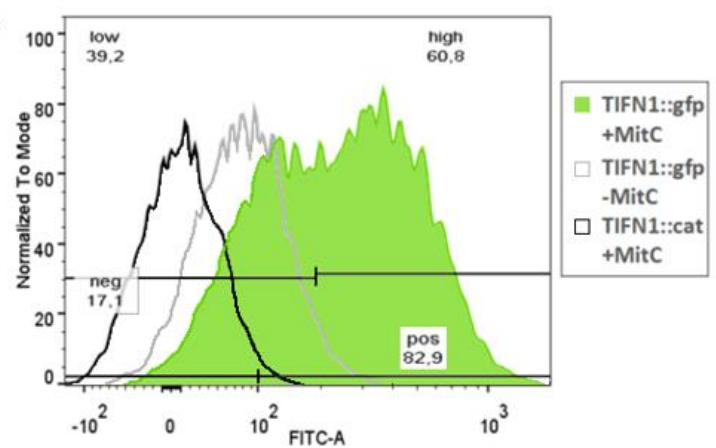

Figure 1. Phage labelling and examination of phage replication. (A) Schematic drawing of the prophage genome with marked $g f p$ and cat insertion sites. Arrows represent ORFs and indicate the direction of gene transcription. The number of arrows does not reflect the real ORF numbers but is only a schematic presentation. The insertion was made in between two convergent ORFs. Colors in arrows schematically represent different phage gene clusters. (B) Growth response of TIFN1::gfp to MitC treatment. (C) Phage release by TIFN1::gfp during MitC induction. Green symbols represent MitC treated cultures, grey symbols represent control cultures without MitC. (D) Dynamics of phage replication (as derived from average cell fluorescence intensity) during MitC induction (green symbols) and in uninduced samples (grey symbols) in reporter strain (TIFN1::gfp) compared to base-line fluorescence of non-gfp cultures (TIFN1::cat, black and grey lines for induced and uninduced conditions respectively). (E) Fluorescence distribution in the population at 3 hours of induction in non-gfp TIFN1::cat (black unfilled), uninduced TIFN1::gfp (grey unfilled), and MitC induced TIFN1::gfp (green filled) cultures. The statistics in (e) is shown for induced TIFN1::gfp: $82.9 \%$ of the population was positive for green fluorescence (pos 82.9), $17.1 \%$ was fluorescence-negative (neg 17.1); $60.8 \%$ was highly fluorescent (high 60.8 ) and $39.2 \%$ was low in 
A.

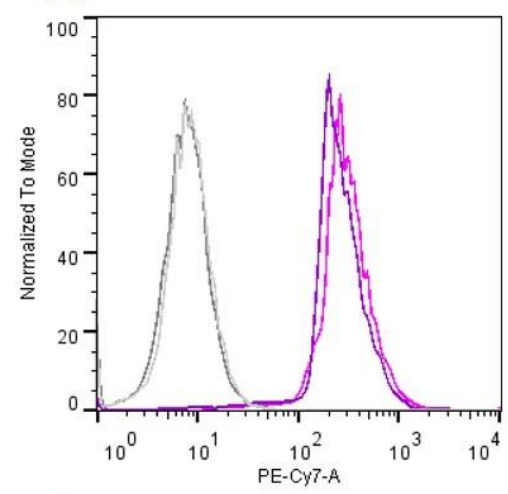

D.

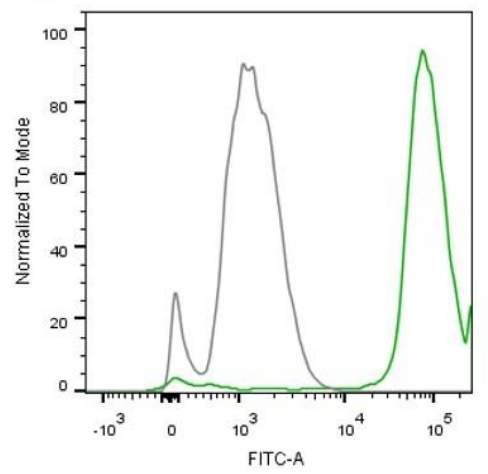

B.

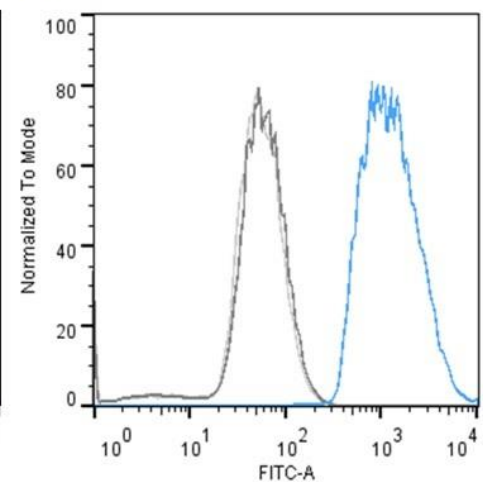

E.

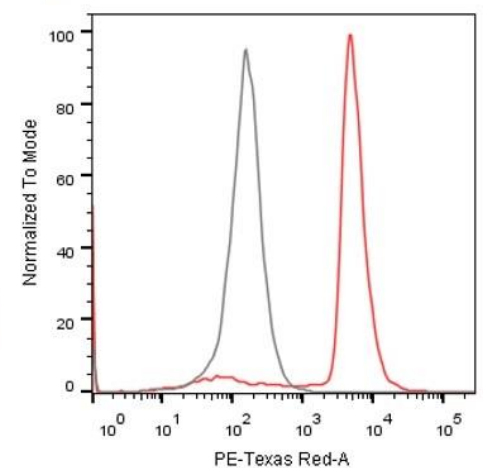

C.

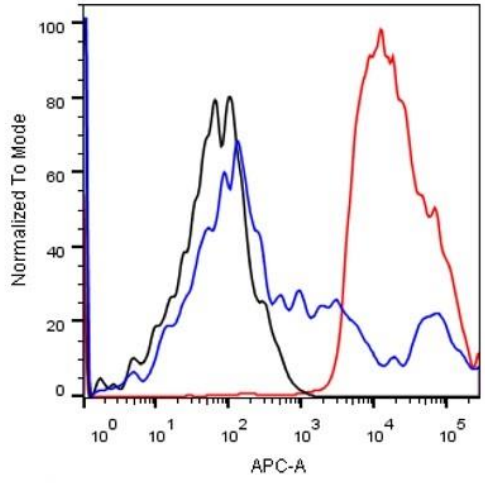

F.

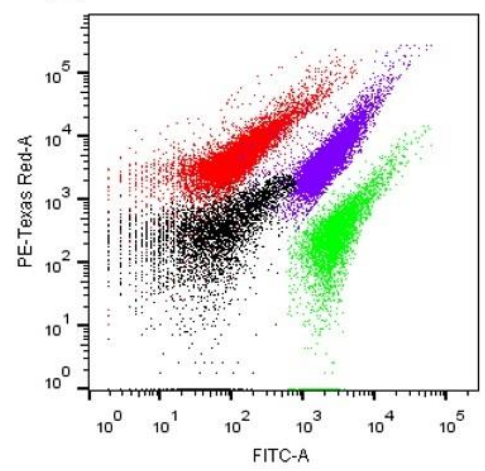

634

A.

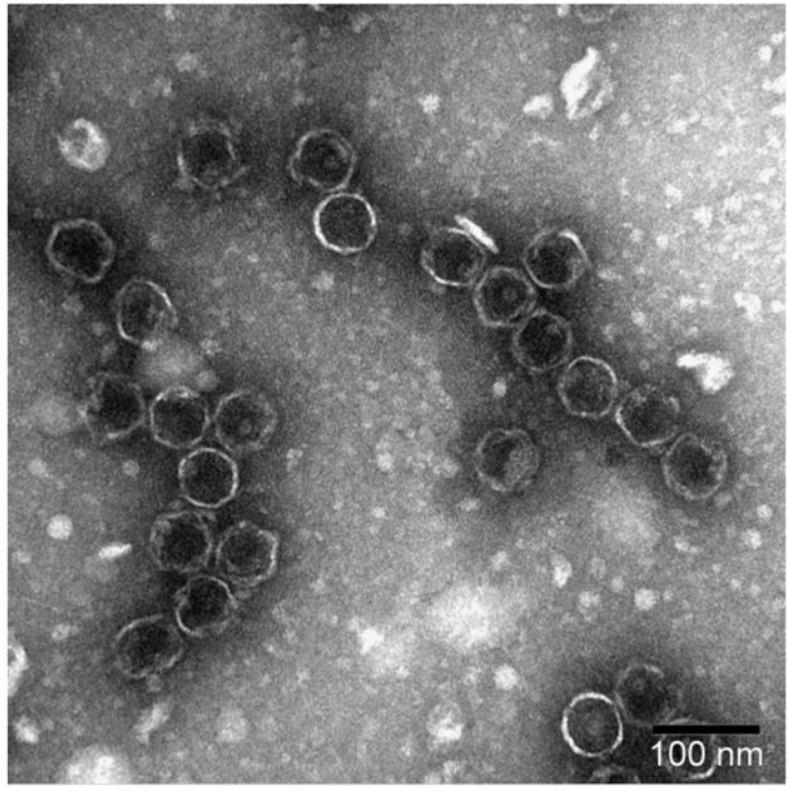

B.

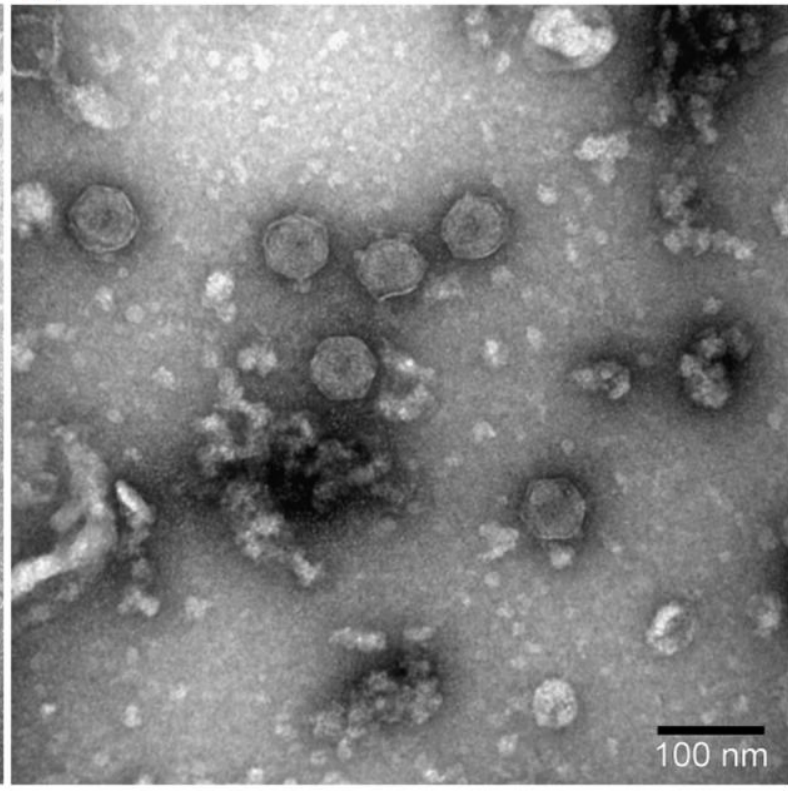

Figure 2. Staining proPhi1 particles with various lipophilic (A, B, C, F) and DNA binding (D, E, F) dyes followed by flow cytometry analysis. Grey/black - unstained phage particles. (A) Lipophilic dye 1; (B) Lipophilic dye 2; (C) Lipophilic dye 3, the blue line represents the sample stained after chloroform treatment; (D) DNA dye 1; (E) DNA dye 2; (F) superimposed dot plot of proPhi1 particle samples with different staining: unstained (black), lipophilic dye 2 (green), DNA dye 2 (red), and double stained lipophilic dye 2 and DNA dye 2 (purple-blue).

\section{Figure 3. Transmission electron micrograph of proPhi1 with (A) and without (B) chloroform treatment.}




\section{A. proPhi1}

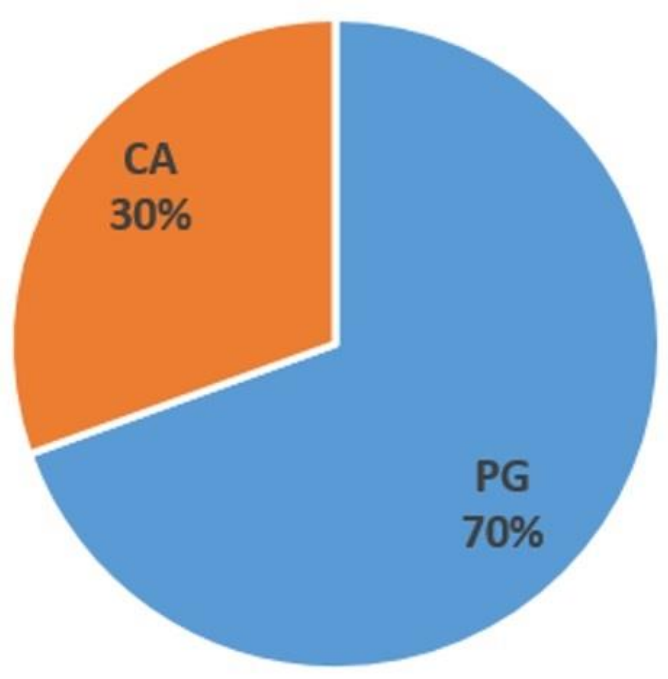

B. TIFN1

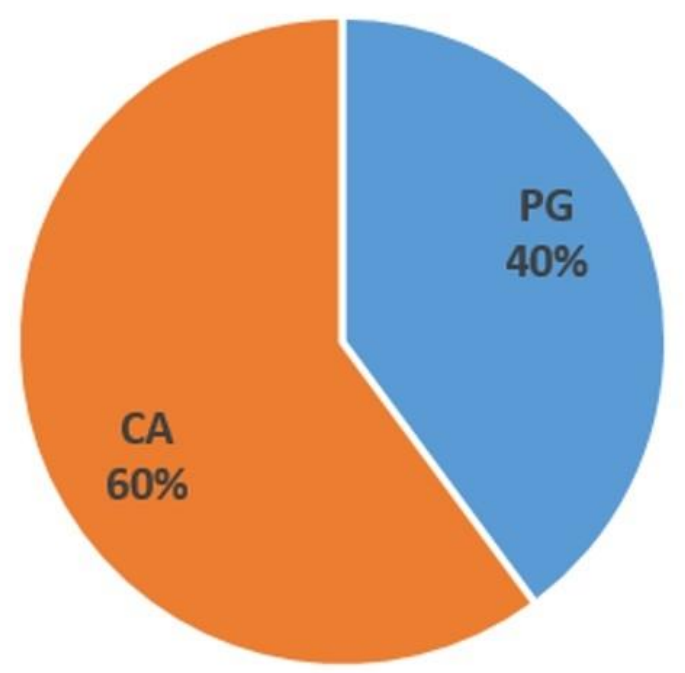

644
645

646

647
Figure 4. Phage and cell lipid composition. Composition of lipids extracted from A) isolated proPhi1 phage particles and (B) TIFN1 whole cell-derived protoplast. PG, phosphatidyl glycerol; CA, cardiolipin. 

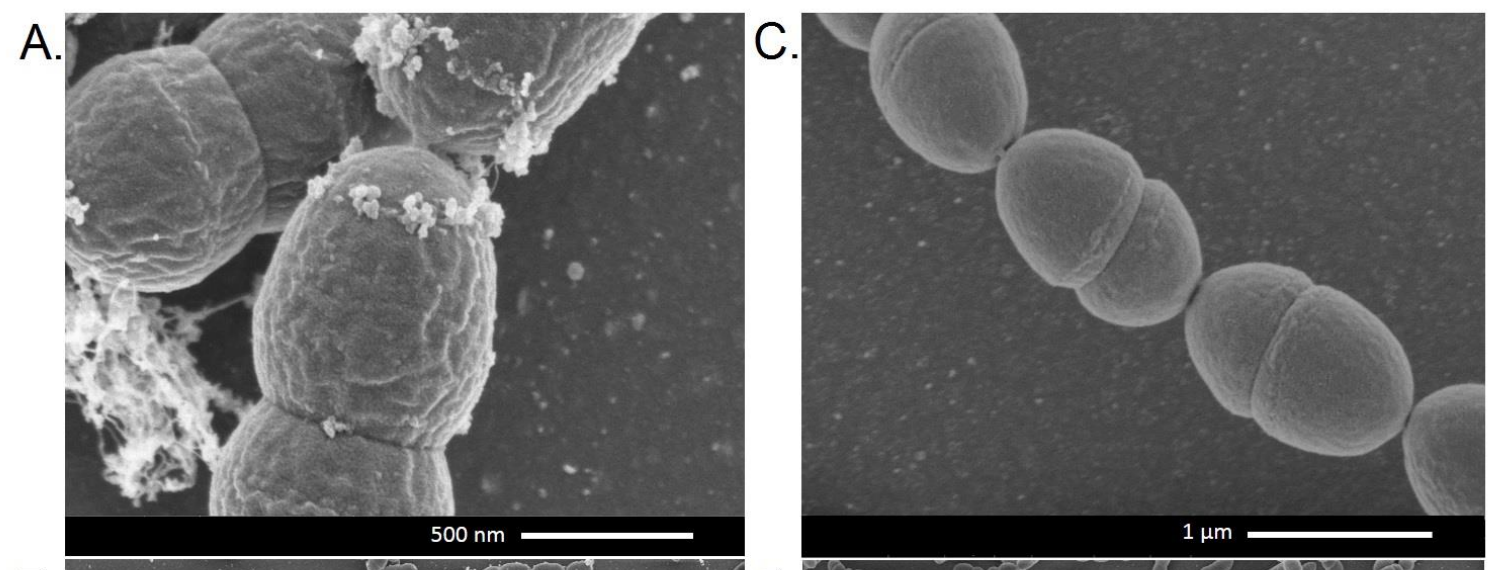

B.
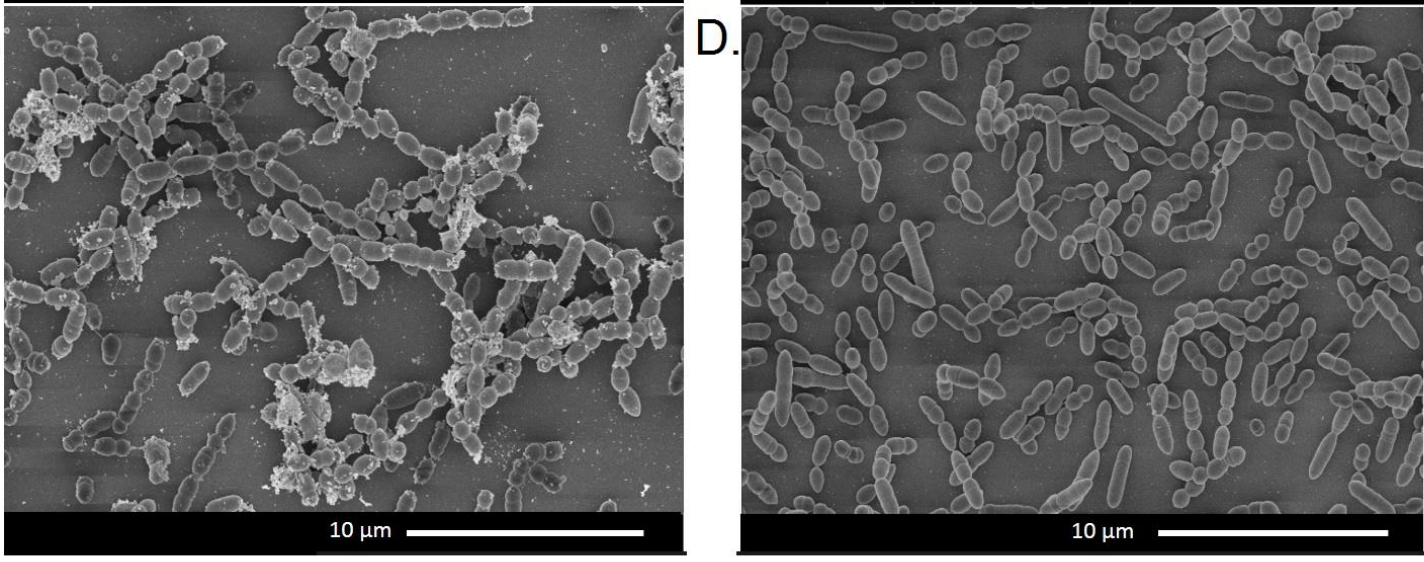

648

649

650

651

Figure 5. Scanning electron micrograph of cells subjected to $6 \mathrm{~h}$ MitC treatment. (A) and (B) TIFN1, (C) and (D) TI1c.

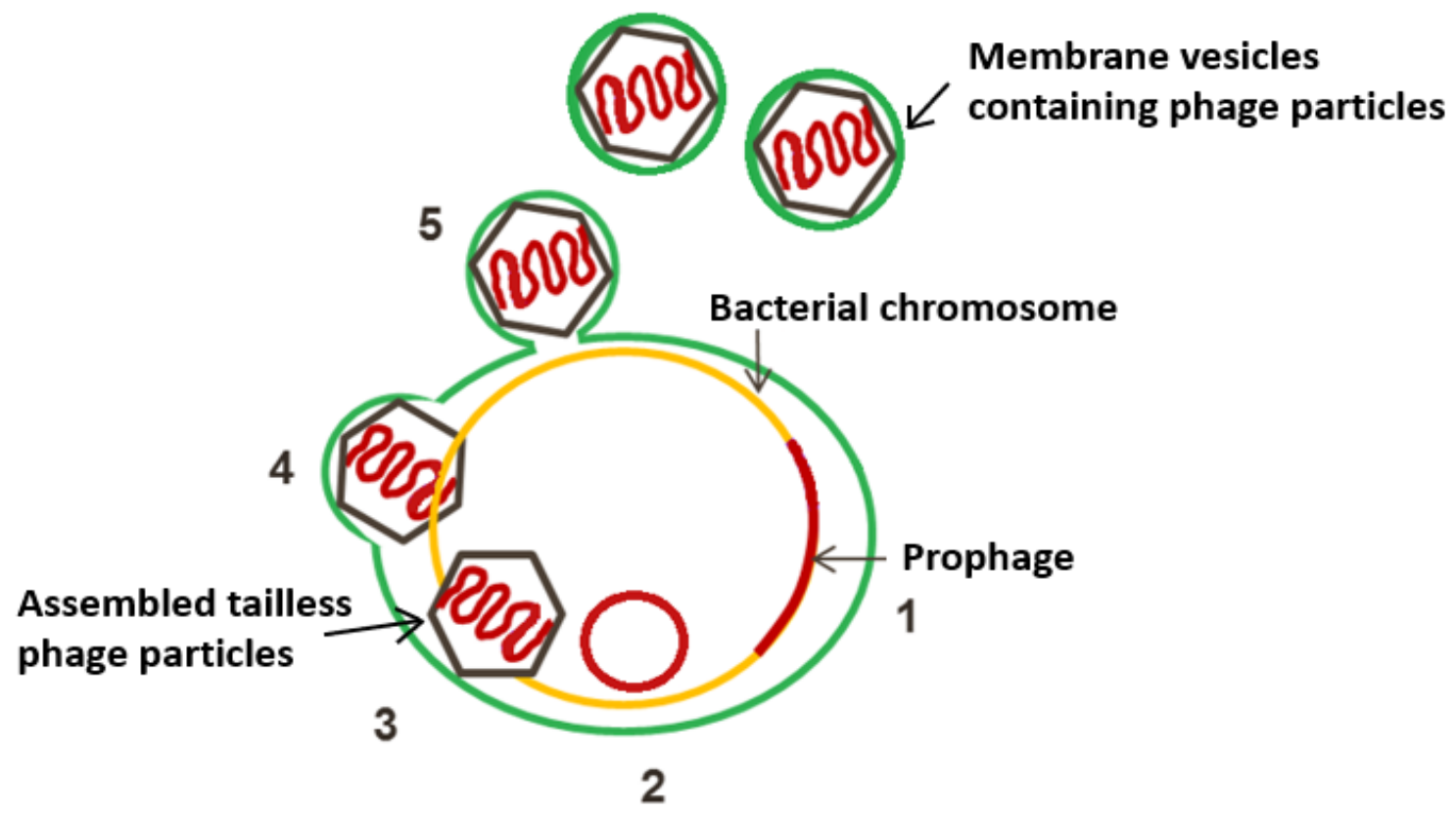

Figure 6. Schematic presentation of the proposed mechanism (step 1-5) of phage release from Lactococcus lactis TIFN1. Activation of proPhi1 (step 1 and 2) results in production of tailless Siphoviridae phage particles (3), 
bioRxiv preprint doi: https://doi.org/10.1101/2021.07.21.453303; this version posted July 23, 2021. The copyright holder for this preprint (which was not certified by peer review) is the author/funder. All rights reserved. No reuse allowed without permission.

enclosed in lipid membrane derived from the cytoplasmic membrane (green) (4), and released from the cells by

656 a budding-like, non-lytic mechanism (5). 
659

660

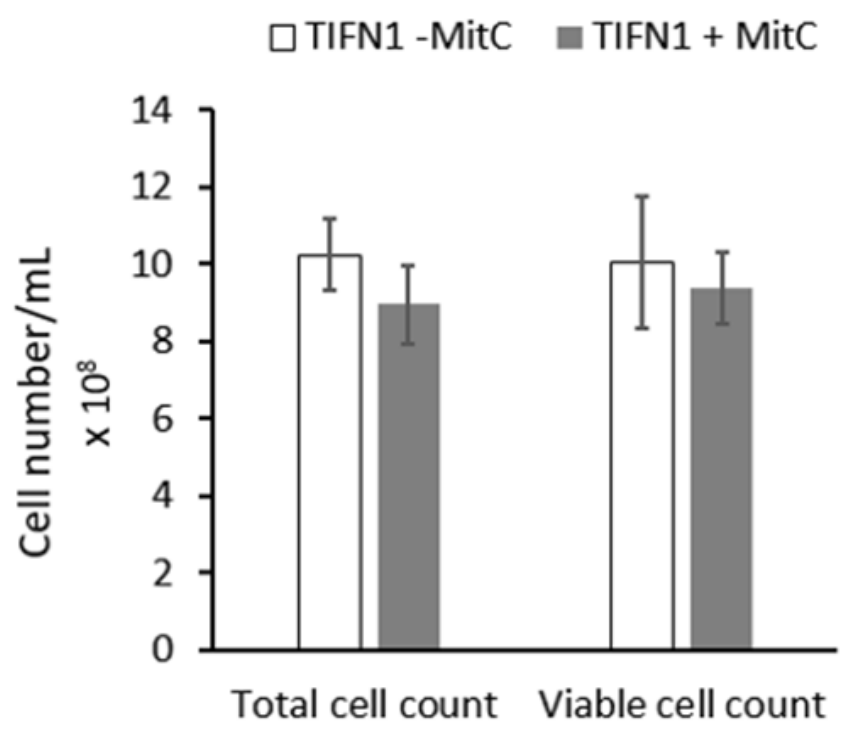

661

Figure S1. Cell count of Lactococcus lactis strain TIFN1 under phage induction conditions. Total cell count

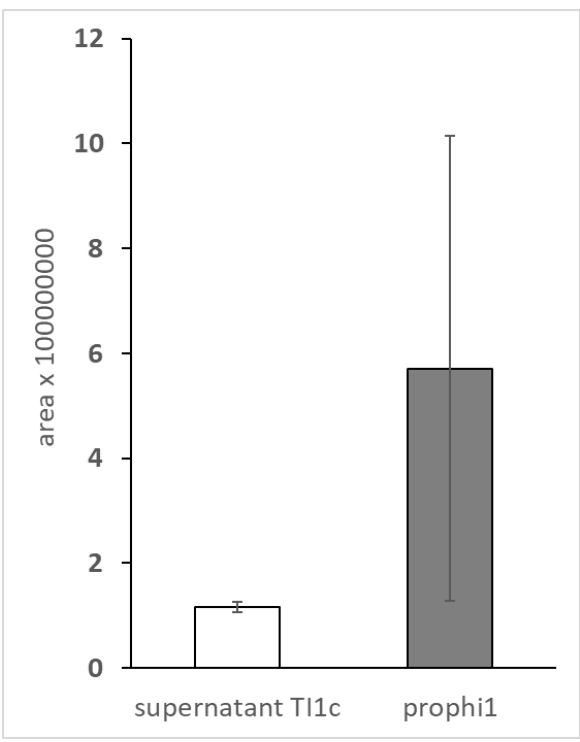

